\title{
O PROGRAMA DE INTEGRAÇÃO DA EDUCAÇÃO PROFISSIONAL COM A EDUCAÇÃO BÁSICA NA MODALIDADE DE EDUCAÇÃO DE JOVENS E ADULTOS (PROEJA) NO IFG-CÂMPUS GOIÂNIA: UM PERCURSO CONTRADITÓRIO NA CONSTRUÇÃO DO DIREITO À EDUCAÇÃO
}

\author{
J. M. B. VITORETTE* E M. D. R. CASTRO \\ Instituto Federal de Goiás \\ mdrcastro16@gmail.com*
}

Artigo submetido em fevereiro/20160 e aceito em março/2016

DOI: $10.15628 /$ holos.2016.2798

\section{RESUMO}

Este trabalho se propõe discutir algumas nuances de como o processo de implantação e implementação do PROEJA no Câmpus Goiânia tem se desenvolvido. A construção dessa trajetória, em última instância, visa elucidar a efetivação (ou não) do direito à educação aos estudantes da Educação de Jovens e Adultos. Para tanto, vale-se da análise de dados coletados junto aos gestores, professores e alunos dos cursos Técnicos Integrados em
Serviços de Alimentação e Cozinha e também daqueles provenientes dos documentos relativos ao PROEJA, construídos dentro e fora do IFG- Câmpus Goiânia. Tais dados foram confrontados com as discussões teóricas sobre a Educação de Jovens e Adultos e Educação Profissional inseridas em uma sociedade cujos fundamentos emergem de uma sociedade dependente em relação aos países centrais do capitalismo.

PALAVRAS-CHAVE: PROEJA, IFG, implantação, direito.

\section{PROFESSIONAL EDUCATION INTEGRATION PROGRAM WITH BASIC EDUCATION IN TYPE OF YOUTH AND ADULT EDUCATION (PROEJA) IN IFG-CAMPUS GOIÂNIA: A CONTRADICTORY JOURNEY IN CONSTRUCTION RIGHT TO EDUCATION}

\begin{abstract}
This work proposes to discuss some nuances about how the process of implantation and implementation of PROEJA in Campus Goiânia has been developed. The construction of this trajectory, finally, aims to elucidate (or not) the realization of the education right to the students of Education of Youth and Adults. This occurs through the analysis of collected data with managers, teachers and students of the Integrated Technical
\end{abstract}

Courses in Food and Kitchen Services and also through documents data related to PROEJA, constructed inside and outside IFG-Campus Goiânia. These were confronted with the theoretical discussions about Education of Youth and Adults and Professional Education inserted in society whose foundations arise from a dependent society in relation to capitalist central countries.

KEYWORDS: PROEJA, IFG, implantation, right. 


\section{INTRODUÇÃO}

Atualmente, o Instituto Federal de Goiás (IFG) oferta dezoito cursos técnicos integrados na modalidade de Educação de Jovens e Adultos por meio do Programa Nacional de Integração da Educação Profissional com a Educação Básica na modalidade de Educação de Jovens e Adultos. Tais cursos estão distribuídos da seguinte forma: em Goiânia - Cozinha, Informática, Transporte Rodoviário; em Itumbiara - Agroindústria; em Uruaçu - Comércio; na Cidade de Goiás Artesanato; em Jataí - Secretariado; em Inhumas - Panificação; em Formosa - Manutenção e Suporte em Informática e Edificações; em Aparecida de Goiânia - Panificação e Modelagem do Vestuário; em Anápolis - Secretaria Escolar e Transporte de Carga; em Águas Lindas - Enfermagem; em Goiânia Oeste - Enfermagem; em Senador Canedo - Refrigeração e Climatização; em Valparaíso - Eletrotécnica (IFG, 2014).

O total de cursos indica, mais que uma quantidade, a construção, em última instância, de uma história cuja perspectiva é a materialização do direito à educação. Trata-se de processo que, contudo, vai se estabelecendo mediante lutas políticas e tomadas de decisões, fazendo emergir o contraditório, os limites, mas também as possibilidades e perspectivas de democratização do acesso aos sujeitos da Educação de Jovens e Adultos em instituições até então frequentadas, majoritariamente, pelas classes médias.

A tensão estabelecida entre afirmação e negação no que diz respeito ao Programa é induzida pelas contradições presentes na sociedade e educação brasileira - em especial aquelas oriundas da Educação Profissional e Tecnológica e da Educação de Jovens e Adultos. Assim, temse um Estado autocrático e sincrético que, visando à expansão e manutenção da ordem capitalista, assume a educação e as políticas daí advindas como instrumento de afirmação dessa ordem (Fernandes, 1975). Na atual conjuntura, as políticas educacionais nessas modalidades propõem a elevação da escolaridade e a qualificação dos trabalhadores - estudantes da EJA -, de um lado, procurando atender às demandas da produção "flexível" em um país dependente. De outro, parcelas da sociedade civil - dentre elas as que atuam no interior dos institutos - buscam dar caráter emancipador, democrático e perene às políticas e ações destinadas aos estudantes da EJA e à Educação Profissional e Tecnológica.

A revelação das contradições, limites e perspectivas do PROEJA no IFG será analisada a partir da implantação e implementação do Programa no Câmpus Goiânia, por meio do Curso Técnico Integrado em Serviços de Alimentação e, depois, pelo Curso Técnico Integrado em Cozinha, que substituiu o primeiro em 2010 para atender às orientações do Catálogo Nacional de Cursos Técnico.

\section{O PROEJA NO CÂMPUS GOIÂNIA E A TRAJETÓRIA DE UMA AÇÃO FOCALIZADA}

Com o estabelecimento do Decreto no 5.478, de 24 de junho de 2005 (Brasil, 2005), abremse possibilidades para a incorporação, de forma mais articulada, no âmbito da Rede Federal de Educação Profissional e Tecnológica, da oferta da Educação de Jovens e Adultos.

Em 2005, servidores do antigo Centro Federal de Educação Tecnológica de Goiás participaram das oficinas pedagógicas de capacitação oferecidas pelo MEC e, logo após, reuniões 
com as Coordenações de Áreas foram realizadas para avaliação das ofertas de cursos técnicos na modalidade Educação de Jovens e Adultos. Com a obrigatoriedade de oferta de um quantitativo de vagas pela instituição, a deliberação final, contudo, ficou a cargo das coordenações.

Após as reuniões, apenas a Coordenação de Turismo e Hospitalidade, dados os princípios contidos no seu projeto político-pedagógico - que era o de "fortalecimento da instituição pública, gratuita e de qualidade, e da inclusão social" -, mostrou-se favorável à oferta dessa modalidade (CEFET-GO, 2006, p. 5). Assim, decidiu-se pela abertura do Curso Técnico Integrado em Serviços de Alimentação.

Segundo entrevistas, a assunção do Programa - e a consequente elaboração do projeto do curso - ocorreu a partir da iniciativa dos professores, cuja coordenação ainda estava se consolidando e que era receptiva à ideia da inclusão social. Nesse sentido são exemplares as seguintes falas:

Isso foi uma reivindicação dos professores, não foi uma reivindicação da instituição, a implantação do Curso Técnico em Serviço de Alimentação na modalidade de Jovens e Adultos. (Gestor 1).

Eu entendo que é um grupo de docentes que tem um comprometimento com o projeto do PROEJA e que, portanto, tem levado a bom termo o desenvolvimento das ações no Câmpus Goiânia. (Gestor 2).

As justificativas para a não adesão das demais coordenações respaldaram-se no não repasse de recursos financeiros para a estruturação e reestruturação dos laboratórios e na não contratação de servidores docentes e técnico-administrativos para os cursos a serem ofertados nessa modalidade. Contudo, durante as reuniões realizadas com as coordenações, emergiram das falas razões vinculadas ao papel da instituição e ao perfil de cursos a serem ofertados, notando-se o interesse em ofertar cursos de pós-graduação e cursos técnicos mais complexos, não condizentes com o público da Educação de Jovens e Adultos (Silva; Oliveira, 2007).

O fato de abrir o primeiro curso na modalidade EJA mostra que o IFG permite o acesso a esses estudantes no seu interior. Contudo, como ressaltado por Ventura (2008), é na compreensão do caráter do acesso e das ofertas, nas suas diferentes formas, que se revela o espaço destinado a esses estudantes na instituição e na sociedade. No caso do IFG, Câmpus Goiânia, a assunção do Programa não ocorreu de maneira orgânica, como parte da política institucional - como já destacado -, o que indica um interesse restrito pelo seu desenvolvimento, tomado mais como exceção do que como parte constitutiva do seu projeto. A natureza focal da assunção deste Programa no interior da Instituição é reafirmada também em âmbito externo (ações governamentais), na medida em que ele não vem com a força política e financeira capaz de empreender mudanças significativas em instâncias que trazem uma série de práticas administrativas, pedagógicas, políticas e culturais - consolidadas, geralmente conservadoras e pouco democráticas, bem de acordo com a estrutura do Estado brasileiro. Contudo, cabe destacar que, mesmo diante de tais limitações, o Programa começou a questionar a "ordem estabelecida" e fazer emergir as contradições. 


\section{FOMENTANDO CONTRADIÇÕES: O PROEJA NOS CÂMPUS GOIÂNIA E UMA NOVA FORMA DE ACESSO}

Mesmo sendo uma ação isolada e não tendo ainda um caráter institucional, na construção do projeto político-pedagógico do curso Serviços de Alimentação, diante das especificidades do público da EJA, como destacado por Paiva (2004) e Arroyo (2005), optou-se por uma forma de entrada que enfatizasse a disposição dos estudantes em realizar o curso. Por conseguinte, 0 processo seletivo de 2006/2 e 2007/1 foi feito por sorteio e com inscrição gratuita, diferente da tradicional entrada realizada com provas sobre os conteúdos das diversas áreas.

Essa forma de acesso é reconhecida, como manifestado por um aluno, como instrumento de aproximação da instituição com a realidade vivida por eles. Assim, ressalta que é "um processo seletivo que exclui, porque não há vagas para todos, mas que também não exclui, pois ainda não tem outra forma, é ainda o melhor para nós" (Discente 1). Entretanto, como esses dois processos apresentaram problemas e era necessário chegar mais próximo ao público da EJA, decidiu-se pelo acréscimo de palestra e entrevista.

Outro problema que persistia dizia respeito à pouca divulgação e à consequente baixa procura pelo curso. Sendo assim, foi feita uma chamada pública para completar as cinco vagas que ainda estavam em aberto. As estratégias utilizadas foram o pedido de divulgação junto ao Fórum Goiano de Educação de Jovens e Adultos, que agrega vários segmentos, e a distribuição de materiais de divulgação em diversos locais da cidade. O resultado do esforço foi que, "para as 5 vagas, houve a inscrição de 120 candidatos. No processo seletivo de janeiro de 2008, foram 270 candidatos inscritos para 30 vagas, ou seja, 9 candidatos por vaga "(Gestora 3).

Em 2008, os critérios de inscrição do curso continuavam, portanto, os mesmos, ou seja, o curso destinava-se às pessoas com idade mínima de 17 anos, que não tinham concluído o ensino médio e que, no ato da matrícula, comprovassem, por meio de documento legal, a idade e a conclusão do curso. De 2007/02 a 2008, o sorteio seria feito caso houvesse mais de 120 inscritos (CEFET-GO, 2008).

Em 2009, o sorteio passou a ser feito se o número de inscritos fosse superior a 240 e estabeleceram-se um roteiro de entrevista e uma tabela de pontuação para esse processo. Instituiu-se, ainda, uma declaração, no ato da inscrição, que o candidato deveria preencher afirmando que não possuía o ensino médio e reformulou-se a ficha contendo os aspectos socioeconômicos e culturais dos candidatos (IFG, 2009).

Já em 2010, a idade mínima para se inscrever no processo seletivo do curso passou a ser 18 anos. Houve mudança também na ordem do processo seletivo, ou seja, a palestra passou a ser feita em primeiro lugar, tendo caráter eliminatório, foi seguida do sorteio, caso comparecessem mais de noventa candidatos, e depois era realizada a entrevista. Além disso, o processo seletivo passou a ser realizado em um único dia e exigiu-se uma declaração do candidato afirmando que possuía o certificado ou diploma de conclusão do ensino fundamental (IFG, 2010).

De 2011 até a presente data, as formas de realização do processo seletivo são a palestra, o sorteio e a entrevista. As inscrições ainda são via internet. No processo feito para ingresso de estudantes em 2015/1, para o quantitativo de 510 vagas, houve 1.845 inscritos, assim distribuídos, considerando a disponibilização de trinta vagas por curso (todos técnicos integrados): Águas Lindas de Goiás, curso em Enfermagem, 11,3 candidatos por vaga; Anápolis, curso em Secretariado 
Escolar, 3,1 por vaga, e Transporte de Cargas, 4,1 por vaga; Aparecida de Goiânia, curso em Modelagem do Vestuário, 2,5 por vaga; Cidade de Goiás, curso em Artesanato, 1,8 por vaga; Formosa, curso em Edificações, 1,9 por vaga; Goiânia, curso em Cozinha, 3,8 por vaga, curso em Informática para a Internet, 6,2 por vaga, e curso em Transporte Rodoviário, 2,6 por vaga; Goiânia Oeste, curso em Enfermagem, 7,8 por vaga; Inhumas, curso em Panificação, 0,8 por vaga; Itumbiara, curso em Agroindústria, 1,8 por vaga; Jataí, curso em Secretariado, 1,3 por vaga; Senador Canedo, curso em Refrigeração e Climatização, 2,6 por vaga; Uruaçu, curso em Comércio, 1,7 por vaga; e Valparaíso de Goiás, curso em Eletrotécnica, 5,9 por vaga (IFG, 2015).

$\mathrm{Na}$ análise de Moll (2010, p. 135), um dos desafios colocados pelo PROEJA é o dimensionamento da forma de acesso às instituições como os IFETs. Refere que "o retorno à escola não é uma tarefa simples para quem já deixou a escola há muito tempo ou que saiu por ver expectativas exauridas e sonhos frustrados [...], [o que exige] modificar o consagrado vestibular $[\ldots]^{\prime \prime}$.

Os processos e instrumentos criados para a obtenção de acessos mais compatíveis com o público da EJA demonstram que esse campo não é apenas rico em inovações pedagógicas (Arroyo, 2005), mas também em inovações administrativas e organizacionais. Trata-se de campo que induz ao desenvolvimento de práticas educativas mais próximas dos sujeitos reais, com as suas pretensões imediatas e potenciais, uma vez que sua permanência nas instituições vincula-se significativamente a tal compreensão.

\section{DIFICULDADES DE ASSUNÇÃO DO PROEJA NO IFG-CÂMPUS GOIÂNIA}

Durante o processo de implantação dos cursos vinculados ao PROEJA no IFG a instituição promoveu duas especializações, mediante a participação em editais lançados pela Setec, bem como uma chamada pública para capacitação de servidores e a entrada em uma rede de pesquisa vinculada ao PROEJA. Trata-se de processos formativos destinados a servidores que não tinham experiência profissional com essa modalidade de educação. Contudo, ao longo de oito anos de implantação e implementação - de 2006 a 2014 -, internamente houve pouca adesão aos processos formativos.

A não participação de servidores foi justificada pelo fato de que um curso de especialização não correspondia à demanda de qualificação dos servidores, cujo interesse era pelos de stricto sensu. Contudo, o que se verifica é que o pouco interesse da comunidade por esse público decorre de um possível comprometimento da qualidade do ensino da Instituição, por se tratar de estudantes com dificuldades de aprendizagem, que não têm uma "base", o que dificultaria a consolidação de um "centro de excelência", como se verá a seguir. Por isso, nem mesmo um curso de formação continuada, que demandaria um tempo menor, mas que cumpriria o papel de capacitar os servidores para esta modalidade de educação, não se efetivou. Sobre essa questão, um professor participante do Encontro Diálogos PROEJA lembrou que "um dos mitos entre o corpo docente da instituição e na sociedade em que a gente vive é que para dar aulas na EJA é preciso abaixar o nível daquilo que a gente deve ensinar" (Professor 1).

Maron (2009) também assinala que na UTFPR os professores não se inscreveram nas primeiras turmas da especialização. Diz ainda que na primeira turma ofertada na unidade de Curitiba não havia nenhum participante do curso de especialização. Debiásio (2010) chama a 
atenção para a importância da capacitação a professores e gestores que atuam no PROEJA. Recuperando os indicativos contidos no Documento Base (Brasil, 2007), Debiásio (2010, p. 48) refere que a formação para esse campo multidimensional agrega, "simultaneamente, conteúdos e funções da educação básica na modalidade EJA e da educação profissional, situação inédita na educação brasileira" e precisa desenvolver um campo teórico sólido que respeite as especificidades dos sujeitos da EJA no momento da sua aprendizagem. Isto porque, apesar de a educação brasileira ter certa experiência com a educação profissional e a educação de jovens e adultos, "a rede pública de educação profissional brasileira tem pouquíssima experiência com a EJA, bem como as escolas que ofertam especificamente a EJA também não apresentam, historicamente, experiência com a educação profissional" (Debiásio, 2010, p. 48).

Para Maron (2009, p. 152), a formação de professores e gestores é uma necessidade, "para que o PROEJA se firme como política pública permanente de educação". Argumenta ainda que essa capacitação cobriria uma lacuna na formação inicial dos professores, não contemplada nos cursos de graduação, assim como ajudaria no desenvolvimento de um ensino de qualidade, evitando a evasão dos educandos dos espaços escolares.

Entretanto, apesar da pertinência e necessidade de os professores buscarem a formação nesse novo campo educacional e epistemológico, o que se percebe é uma resistência dos professores e gestores do IFG-Câmpus Goiânia em relação ao PROEJA, retratada também na sua não participação nos cursos de capacitação. Afinal, como se viu, o PROEJA é uma exceção dentro da Instituição e, como tal, não se coloca como premente uma formação vinculada a ele.

Outra dificuldade de assunção do Programa vincula-se à resistência interna em relação ao PROEJA. Para tanto corroboram as entrevistas, destacando a falta de uma ação mais incisiva da gestão para a implantação do programa, a dificuldade em trabalhar com pessoas mais velhas ou que têm dificuldade de aprender e a falta de estrutura física e humana da Instituição para a abertura de mais cursos. Também foram referidos desconhecimento em relação à Educação de Jovens e Adultos e a priorização por parte da comunidade em trabalhar com o ensino superior. É o que sugerem as seguintes falas:

Então, você pega um quadro de professores que está habituado a trabalhar com jovens, com adolescentes, jovens e adolescentes em idade escolar, que passa por um processo seletivo bastante concorrido. De onde a gente pega só os melhores. Os mais qualificados. Talvez quando entra um público com um grau de dificuldade maior, ele possa de certa forma aí trazer uma resistência ao quadro docente [...]. (Gestor 2).

Essa visão estigmatizada, ela continua persistindo, e ela vem hoje agregada a uma ideia de que os cursos dominantes aqui na Instituição, que são os cursos na área tecnológica, eles se constituem, assim, de cursos com grau de dificuldade, e esse público de jovem e adulto teria muita dificuldade em acompanhar, em corresponder. Então são cursos bastante focados em uma base de formação mais complexa dos conteúdos ligados às ciências exatas, esses cursos seriam, portanto, cursos que não teriam perfil para esta clientela de jovens e adultos. (Gestor 5).

As causas elencadas demonstram que as justificativas para a resistência são em certa medida condizentes com as condições historicamente construídas de oferta dos chamados cursos regulares. Daí se poderia entender que, de acordo com essa trajetória, a instituição não teria como 
atender bem um novo público sem o devido apoio institucional, sem a preparação formativa dos docentes e sem a expansão das condições físicas e humanas. Nessa situação, seria mais apropriado ampliar a sua oferta em níveis e modalidades já conhecidos ou propiciar o prolongamento deles. A resistência tomaria aí uma dimensão positiva, no sentido de problematizar aspectos importantes e necessários para a implementação de uma ação cuja natureza demanda novos conhecimentos e novas condições dentro da instituição.

Contudo, outras falas e ações desenvolvidas no Câmpus indicam que a resistência assume caráter diferenciado.

Por que permite criar um curso de engenharia sem ter professor suficiente pra dar aula, por exemplo? E não se permite criar o PROEJA e deixa o PROEJA ao bel-prazer das pessoas. Eu sinto a necessidade de uma intervenção mais contundente da gestão superior. (Gestor 4).

Eu acho que não há uma compreensão do que de fato é uma educação para trabalhador ou então não se identifica com a classe trabalhadora. [...] tem gente que acredita que tem que dar formação para a elite. E tem gente que acredita, uns poucos, em número menor, na perspectiva do trabalhador. Então existem disputas de concepções dentro da instituição. (Gestor 1).

O caráter submerso dessa resistência deve-se à permanência de uma cultura institucional hegemônica que se forjou historicamente a partir do estabelecimento de lugares educacionais para as classes sociais, como afirma Kuenzer (s.d.), como também, no caso da instituição estudada, à manutenção de relações assentadas no patrimonialismo. O IFG-Câmpus Goiânia, como parte da Rede Federal, ministra a educação profissional e tecnológica - durante muito tempo, identificada com a formação de excluídos e da classe trabalhadora - e foi se constituindo como lócus de um ensino de reconhecida qualidade, tanto no que diz respeito à formação propriamente dita quanto no que se refere à possibilidade do alcance de melhores empregos. Por conseguinte, essa instituição passou a ser frequentada por um público com melhores condições socioeconômicas e com trajetórias formativas mais regulares, distanciando-se daquele público original. ${ }^{1}$ Essa nova condição desembocou na criação de uma estrutura, assim como de normas de ação, códigos, valores, práticas e rituais, enfim, uma cultura institucional própria desse público, mantida, em muitos aspectos, por meio de relações e decisões de natureza pessoal.

A consolidação da Rede Federal de Educação Profissional e Tecnológica como instituição de qualidade acadêmica e profissional, cuja cultura institucional vincula-se a esse público assim como às possibilidades formativas ("de alto nível”) que ela indica, tem gerado os fundamentos das resistências em torno da assunção orgânica do PROEJA. Nessa perspectiva, o IFG-Câmpus Goiânia não se constitui em lugar formativo para esse público. Daí a recusa dos docentes em participar dos cursos de formação que possibilitariam a obtenção de conhecimentos para trabalhar com a EJA e sua opção pela oferta de cursos superiores e de pós-graduação, mesmo sem a garantia de aporte extra de recursos físicos, materiais e contratação de professores, sem a expansão do Programa nesse Câmpus, com a oferta de cursos em outras áreas.

Essa cultura institucional assume, ainda, faceta autoritária e conservadora que induz ao desenvolvimento de atitudes de discriminação e estranhamento em relação ao público da EJA,

\footnotetext{
${ }^{1}$ Corroborou, para esta situação, a formatação de processos seletivos também identificados com esse público.
} 
dificultando a efetivação da educação como direito e a ampliação das relações democráticas. É o que atestam pesquisas mencionadas e as falas a seguir:

Entrar nesta instituição foi encarar os jovens que olham para a gente e falam: "Lá vai os velhinhos do PROEJA, no corredor". Você vai na frente e você está ouvindo eles falarem nas costas. (Discente 1 ).

Eu acho assim, na minha opinião, [quanto à] discriminação, cabe à gente aceitar ou não, eu sou mais eu. Mas, assim, a gente ouve o comentário, [percebe] a discriminação. [...] O professor tem que aceitar as pessoas com as diferenças que elas têm. (Discente 2).

A entrada da EJA no IFG-Câmpus Goiânia acentuou as contradições e fez emergir ações, comportamentos e compreensões conservadoras que acabam por reproduzir aspectos da sociedade brasileira e a constituição do seu Estado. No entanto, tal ingresso permitiu a problematização dessas mesmas posturas e a oxigenação do debate interno, indicando a necessidade de sua superação se a perspectiva for o crescimento e o desenvolvimento da nação, visto que a universalização da educação básica e a afirmação do direito à educação são seus componentes fundantes.

\section{AS PERSPECTIVAS DO PROEJA NO IFG-CÂMPUS GOIÂNIA}

Este estudo aponta algumas das possibilidades para a consolidação do Programa, no que diz respeito à assunção do PROEJA como política institucional e de Estado. $O$ financiamento, nessa condição, torna-se aspecto indutor relevante da sua efetivação. O pouco envolvimento das coordenações de área e diretoria-geral com o PROEJA remete à discussão sobre o papel político da gestão, "que requer sempre uma tomada de posição" (Dourado, 2008, p. 82). Isso ainda não foi feito pelos gestores, como se percebe pelas falas, o que dificulta a aceitação do PROEJA por parte da comunidade. Para uma possível reversão desse quadro, Nogueira $(2002$, p. 32$)$ propõe que se atue

[...] não como técnicos mais ou menos, mas como intelectuais. ${ }^{2}$ Não como pessoas que se diferenciam por trabalhar mais com as idéias do que com as coisas, por dominar a palavra e habitar as regiões mais elevadas do pensamento abstrato. Mas como pessoas que constroem e organizam, que atuem como "persuasores permanentes" e que são capazes de fixar parâmetro de sentido para os demais.

Além da atuação "dirigente" dos gestores, ressalta-se a importância de transformação do Programa em política pública de Estado como forma de ampliar a presença da EJA na instituição, por meio da oferta de cursos em diversas áreas profissionais. Essa proposição corrobora a necessidade de que as ações governamentais deixem de ter caráter focal e compensatório e passem a atuar na perspectiva de efetivação dos direitos sociais.

Por fim, outra possibilidade de expansão e consolidação do PROEJA dá-se cumprindo o Art. 9o, do Decreto no 5.840, de 13 de julho de 2006, que diz: “[...] o acompanhamento e o controle social da implantação nacional do PROEJA será exercido por comitê nacional, em função

\footnotetext{
2 Para Gramsci (2006), o intelectual assume funções dirigentes quando é, ao mesmo tempo, especialista e político. Nessas condições, ele é um organizador de massa de homens, um organizador da "confiança".
} 
consultiva". Assim, um acompanhamento mais de perto, dialogando com as instituições da Rede, chamando para a necessidade de concretização do direito à educação, daria apoio aos grupos internos que se movimentam em torno da implantação e implementação do Programa e fortaleceria a sua expansão e consolidação.

\section{CONSIDERAÇÕES FINAIS}

Pelo exposto é possível afirmar que o processo de implantação e implementação do PROEJA no IFG-Câmpus Goiânia definiu-se por ter sido realizado a partir da iniciativa de um grupo de professores, com o respaldo do Decreto, na época, no 5.478, de 24 de junho de 2005, em uma área acadêmica que estava se constituindo e que contava com a presença de pessoas (também em nível de gestão) sensíveis às propostas de inclusão social e de abertura da Instituição às demandas sociais. Sobre essa situação, é pertinente destacar a análise que Dagnino (2002, p. 287) faz em relação à importância da presença de indivíduos em posição-chave nas instâncias diretivas comprometidas com projetos emancipatórios.

Esse grupo de professores conseguiu reconhecer os diferentes interesses, ter a capacidade de negociação sem perder a autonomia, construir o interesse público e participar da formulação de políticas públicas que expressam esses interesses (Dagnino, 2002). Foram amadurecendo e reformulando aspectos do projeto político-pedagógico, do processo seletivo, da capacitação dos servidores, da ação política e das negociações em torno da contratação de pessoal e de materiais e laboratórios necessários à construção de um curso de qualidade.

Trata-se de processo que culminou com a ampliação dos cursos integrados vinculados ao PROEJA no Câmpus Goiânia e foi fruto de intensa luta política e discussões sobre o papel social do IFG no I Congresso do Plano de Desenvolvimento Institucional (PDI), realizado em fevereiro de 2012, quando ficou indicado que cada Departamento de Área Acadêmica dos câmpus deveria ofertar pelo menos um curso relacionado ao PROEJA3(IFG, 2013).

Registre-se que nesse mesmo período houve o lançamento do Programa Nacional de Acesso ao Ensino Técnico e Emprego (Brasil, 2011), pelo governo atual, estabelecendo novos parâmetros para a qualificação dos trabalhadores (público constituído por excelência pelos sujeitos da EJA), como a reposição de itinerários formativos que não enfatizam a elevação da escolaridade ou, quando o fazem, dificultam o acesso dos estudantes-trabalhadores à formação profissional, dada a destinação de dois turnos de sua jornada diária para a conclusão dos cursos técnicos. Ou ainda a destinação de grande quantia de verba pública à iniciativa privada para a oferta de cursos de qualificação profissional. Tudo isso constitui uma conjuntura desfavorável à consolidação de uma formação de trabalhadores emancipadora, que precisa ser investigada, se se quer transformá-la ${ }^{4}$. E essa é uma próxima tarefa...

\section{REFERÊNCIAS}

1. ARROYO, M. G. Educação de jovens e adultos: um campo de direitos e de responsabilidade

\footnotetext{
${ }^{3}$ Ressalta-se, entretanto, que o Departamento II do Câmpus Goiânia ainda não oferta cursos voltados para a Educação de Jovens e Adultos, e o Câmpus Luziânia deixou de abrir vagas para esse público em 2014.

${ }^{4}$ Felizmente, no momento de revisão deste texto, o Câmpus Luziânia abre inscrições para o Curso Técnico Integrado em Manutenção e Suporte em Informática na Modalidade EJA.
} 
pública. In: SOARES, L.; GIOVANETTI, M. A.; GOMES, N. L. (Org.). Diálogos na educação de jovens e adultos. Belo Horizonte: Autêntica, 2005.

2. BRASIL. Ministério da Educação. Exposição de Motivos ao Decreto n 05.478 de 2005. Brasília: Secretaria de Educação Profissional e Tecnológica, 2005.

3. _. Ministério da Educação. Programa Nacional de Integração da Educação Profissional com a Educação Básica na Modalidade de Jovens e Adultos: Documento Base. Brasília: Secretaria de Educação Profissional e Tecnológica, 2007.

4. L__ Lei no 12.513 de 26 de outubro de 2011. Institui o Programa Nacional de Acesso ao Ensino Técnico e Emprego (PRONATEC); altera... Diário Oficial [da] União, Brasília, DF, 27 out. 2011.

5. CEFET-GO. Projeto de implantação do curso de educação profissional técnica de nível médio integrado em serviços de alimentação na modalidade de educação de jovens e adultos (PROEJA). Goiânia, 2006.

6. . Centro de Seleção. Edital no. 008/2008. Goiânia, 2008.

7. DEBIÁSIO, F. de J. M. Acesso, permanência e evasão nos cursos do PROEJA em instituições de ensino de Curitiba-PR. 2010. Dissertação (Mestrado em Tecnologia) - UTFP, Curitiba, 2010.

8. DOURADO, L. F. A escolha de dirigentes escolares: políticas e gestão da educação no Brasil. In: FERREIRA, N. S. C. (Org.). Gestão democrática da educação: atuais tendências, novos desafios. São Paulo: Cortez, 2008.

9. DAGNINO, E. (Org.). Sociedade civil e espaços públicos no Brasil. São Paulo: Paz e Terra, 2002.

10. FERNANDES, F. A revolução burguesa no Brasil: ensaio de interpretação sociológica. Rio de Janeiro: Zahar, 1975.

11. GRAMSCI. A. Cadernos do Cárcere. v. 2. Rio de Janeiro: Civilização Brasileira, 2006.

12. IFG. Coordenação do Proeja e Ações Inclusivas. Goiânia, 2009.

13. IFG. Centro de Seleção. Seleção para a educação profissional - PROEJA: total de candidatos por curso e sexo. Goiânia, 2010.

14. __. Plano de Desenvolvimento Institucional. Goiânia, abr. 2013. Disponível em www.ifgoias.edu.br Acesso 2 de dez, 2014

15. . Site Institucional. Pró-Reitoria de Ensino, 2014. Disponível em www.ifgoias.edu.br. Acesso em: 2 dez. 2014.

16. . Centro de Seleção. Processo Seletivo 2015/1. Goiânia, 2015.

17. KUENZER, A. Z. Exclusão includente e inclusão excludente: a nova forma de dualidade estrutural que objetiva as novas relações entre educação e trabalho. [s.d.]. Disponível em: <http:// forumeja.org. br/go/files/13Exclusãolncludente Acacia Kuenzer_1.pdf>. Acesso em: 2 de dez. 2014.

18. MOLL, J. Proeja e democratização da educação básica. In: MOLL, J. et al. Educação profissional e tecnológica no Brasil contemporâneo: desafios, tensões e possibilidades. Porto Alegre: Artmed, 2010.

19. MARON, N. M. W. Os cursos de especialização do PROEJA como estratégia de formação de professores e gestores. Educere et Educare: Revista de Educação, v. 4 n. 8, 2009. Disponível 
em: <http://www.e-revista.unioeste.br/inde.php/educereeteducare/article/download/.../28 18> Acesso em: 10 abr. 2013.

20. NOGUEIRA, M. A. Administrar e dirigir: algumas questões sobre a escola, a educação e a cidadania. In: MACHADO, L. M.; FERREIRA, N. S. C. (Org.). Política e gestão da educação: dois olhares. Rio de Janeiro: DP\&A, 2002.

21. PAIVA, J. Concepção curricular para o ensino médio na modalidade de jovens e adultos: experiências como fundamento. In: FRIGOTTO, G.; CIAVATTA, M. Ensino Médio: ciência, cultura e trabalho. Brasília: MEC/SEMTEC, 2004.

22. SILVA, Z.C.; OLIVEIRA, L.C. O perfil dos alunos da primeira turma do PROEJA no Centro Federal de Educação Tecnológica de Goiás, da Unidade Goiânia. Relatório Final de Pesquisa.PIBIC. Goiânia: CEFET-Go, 2007.

23. VENTURA, J. P. Educação de jovens e adultos ou educação da classe trabalhadora? Concepções em disputa na contemporaneidade brasileira. 2008. Tese (Doutorado) - Universidade Federal Fluminense, Faculdade de Educação, 2008. 